\title{
Effect of a Designed Nursing Protocol on Nurse's Knowledge and Practice Regarding Unstable Angina.
}

\author{
Zahra A. Said, Zienab A. Mohammad, Amal M. Ahmed, Mervat A. Abd El-Aziz. \\ Assistant lecturer of Critical Care Nursing, Faculty of Nursing, Aswan University, Egypt. \\ Professor of Medical-Surgical Nursing, Faculty of Nursing, Assiut University, Egypt. \\ Assistant Professor of Medical-Surgical Nursing, Faculty of Nursing, Aswan University, Egypt. \\ Lecture of Critical Care Nursing, Faculty of Nursing, Assiut University, Egypt.
}

\begin{abstract}
Background: Unstable angina is a type of ACS. The aim of the study: Assess nurses' knowledge and practice regarding patients with unstable angina, Design nursing care protocol for nurses working within CCU, and evaluate the effect of the nursing protocol on nurse's knowledge and practice. Hypotheses: (1) the post mean knowledge scores of nurses will be higher than their pre mean knowledge scores. (2) The post mean practice score of nurses will be higher than their pre mean practice scores. (3) A positive relationship between knowledge and practice score. Research design: Quasi-experimental a sample of (35) nurse. A study was conducted in CCU at Aswan University Hospital. Tools: Three tools a) structured interview sheet. b) Observation checklist sheet. c) Construction of designed nursing protocol. Results: The hypotheses were supported as improvement in the mean knowledge \& practice scores after implementing of the nursing protocol. The hypothesis was supported by a positive relationship between nurse's knowledge and practice scores after application of the nursing protocol. Conclusion: implementing of designed nursing protocol for patients with unstable angina showed a significant improvement in nurses` knowledge and practice. Recommendations: Nurses are in need for in-service training programs and refreshing courses to improve their knowledge which will reflect into their practice while working with patients.
\end{abstract}

\section{Keywords: Designed Nursing Protocol, Nurse's Knowledge, Practice \& Unstable Angina.}

\section{Introduction}

The incidence of unstable angina in the United States is increasing, and each year, nearly 1 million hospitalized patients have a primary diagnosis of unstable angina. A similar number of unstable angina episodes likely occur outside the hospital and either go unrecognized or are managed in the outpatient setting. However, even with heightened public awareness, improved survival after myocardial infarction (MI), and an aging population, the incidence of unstable angina should continue to rise despite primary and secondary prevention measure (Ahmed, 2014).

Coronary artery diseases (CAD) constitute a major health problem in many parts of the world and are an important cause of morbidity and mortality. It is predicted that by the year 2020, CAD will be the main cause of disability worldwide. In Egypt and other developing countries, there is a definite increase in the incidence of CAD. According to WHO statistics, the age-standardized mortality rates from $\mathrm{CAD}$ are one of the highest worldwide. One possible explanation is the high prevalence rate of CAD risk factors. Hypertension, dyslipidemia, and obesity are common among Egyptians. Unfortunately, systematically documented data on CAD prevalence, incidence and rate of cardiovascular risk factors in developing countries are scarce. (WH R, 2012).
The sharp decrease in infant mortality rate, control of many infectious and parasitic diseases and the progressively increasing average life expectancy of the

population has changed the health profile in many third world countries. Urbanization, sedentary lifestyle, high calorie - high-fat diet combined with increased prevalence of hypertension, cigarette smoking, diabetes mellitus, obesity, dyslipidemia and social stress are important causes of the coming epidemic of CAD in Egypt and other developing countries. This trend should alert the health authorities, medical and scientific community and to take active measures in order to prevent, diagnose and adequately treat these life-threatening disorders (Lee., 2014).

Unstable angina is a condition in which your heart doesn't get enough blood flow and oxygen. It may lead to a heart attack. Angina is a type of chest discomfort caused by poor blood flow through the blood vessels (coronary vessels) of the heart muscle (myocardium). Coronary artery disease due to atherosclerosis is by far the most common cause of unstable angina. Atherosclerosis is the buildup of fatty material called plaque along the walls of the arteries. This causes arteries to become narrowed and 
less flexible. The narrowing interrupts blood flow to the heart, causing chest pain

(N L M., 2013).

Nonmodifiable factors, that influence risk for unstable angina include age, sex, family history, and ethnicity or race. Men have a higher risk than women. Men older than age 45, women older than age 55, and anyone with a first-degree male or female relative who developed coronary artery disease before age 55 or 65 , respectively, are also at increased risk. Modifiable risk factors include hypertension, type 2 diabetes, obesity, cigarette smoking, elevated levels of serum cholesterol, lowdensity lipoprotein cholesterol, and triglycerides; lower levels of high-density lipoprotein cholesterol; a sedentary lifestyle and stress (Dirksen, et al., 2009) Complications that may develop from unstable angina include Myocardial infarction, acute pulmonary edema, congestive heart failure, cardiogenic shock, dysrhythmias, pericardial effusion, cardiac tamponade, cardiac arrest and myocardial rupture( Ian et al.,2009).

The nurse is responsible and accountable for the quality of nursing care given to patients. The single most important protective strategy for the nurse is to be a knowledgeable and safe practitioner of nursing and to meet the standards of care with all patients. Nurses are empowered by the standard of care (SOC) and the trust of the physician and the patient to ensure quality care (Janice et al.,2009).

Aim of the study:

The aim of this study was covered in three folds:

- To assess nurses' knowledge and practice regarding patients undergoing unstable angina,

- To design nursing care protocol for nurses working with coronary care unit

- To evaluate the effect of implementing the designed nursing protocol on nurse's knowledge and practice regarding coronary care unit patients.

\section{Hypothesis}

To fulfill the aim of the study, the following research hypothesis were formulated:

(1) The post mean knowledge scores of nurses who will be exposed to designed nursing protocol will be higher than their pre mean knowledge scores.

(2) The post mean practice score of nurses who will be exposed to designed nursing protocol will be higher than their pre mean practice scores.

(3) A positive relationship will exist between knowledge and practice score obtained by nurses receiving the designed nursing protocol.

\section{Subjects \& Method}

\section{Research design}

Quasi-experimental research design has been utilized in this study.

\section{Setting of the study}

The study was conducted in coronary care unit (CCU) at Aswan University Hospital.

Study subjects

A convenience sample of all available nurses are working in selected setting (about 35 nurses). (14Nursing Technical Institute -21 Diploma) who working in the coronary care unit. and who are willing to participate in the study.

\section{Tools of data collection}

1.Structured interview sheet (pre / post tests), which was developed in a simple clear Arabic language by the researchers based on literature review and experts' opinions in the light of relevant references to assess nurses' knowledge regarding patients undergoing unstable angina. It included the following parts:

- The first part: related to socio-demographic characteristics of the study subjects age, marital status, qualification, years of experience, and attendances of the training program.

- The second part: used to assess nurse's level of knowledge with regard to heart and coronary arteries, nursing care immediate nursing care for chest pain, medication to relieve pain, side effect of medication, routine nursing care, instruction for medication and health education that given to patients before discharge

Scoring system: The total score for all items was 150. Each right answer was given to scores. Those who obtained less than $50 \%$ were considered having an unsatisfactory level of knowledge. While those who obtained from $(50 \%-70 \%)$ or above $70 \%$ were considered having a satisfactory level of knowledge.

2. Observation checklist sheet (pre / post tests): This tool was developed by the researcher based on the current national and international literature to assess standards practice of nurses providing care for unstable angina patients. This tool was used before and immediately after the implementation of the developed nursing care standards to assess the impact of the developed nursing care standards on nurses practice. It consists of the following items:

1- Ensure that CCU room environment is safe to receive the patients.

2- Ensure that all infection control measures are properly followed in CCU.

3- Ensure that nursing care is provided for each patient with unstable angina.

4- Ensure that patients are properly educated before discharge.

Scoring system: Each item was observed, categorized, and scored as follow: 2 for each step that done correct (correctly, in time and with the required frequency) and 1 for each step is done 
incorrect (incorrectly, not in time and without the required frequency) and zero for the step that not done. Inapplicable means that the nurses were not able to apply the principles of the standard due to a shortage of supplies and equipment, not due to shortage or negligence from the nurses. Those who less than (50\%) were considered having an inadequate level. Above $(50 \%)$ were considered having an adequate level.

\section{Construction of designed nursing protocol}

It was developed by the researcher based on nurses needs assessment, literature review, researcher experience and opinions of the medical and nursing expertise. The teaching booklet was revised and modified based on the expertise comments, it was written in Arabic using simple language with illustrations.

\section{Content validity}

It was established by a panel of 5 expertises who reviewed the instruments for clarity, relevance, comprehensiveness, understanding, applicability and easiness for administrative minor modifications were required. The content validity of this tool was checked by expert professors in fields of medicine and nursing and correction was carried out accordingly.

\section{Ethical considerations and human rights}

An official permission to conduct the study was obtained by the researcher from the head of the coronary care unit at Aswan university hospital as well as from head nurses of each unit. Nurses were informed of the purpose and nature of the study. The investigator emphasized that the participation is voluntary and confidentiality and anonymity of the subjects will be assured through coding all of the data.

Tools testing and pilot study

A pilot study was implemented in $10 \%$ of the total study subjects to test the tools. Analyzes of the pilot study revealed that minimal modifications are required. These modifications were done and the subjects were not excluded from the actual study.

\section{Procedures}

- Data were collected at coronary care unit at Aswan University Hospital.

- The tools filled through interviewing. The purpose of the study was explained to the nurses prior to answering the questions. The study was carried out at morning, and afternoon shifts.

- At initial interview the researcher introduce herself to initiate line of communication, explain the nature \& purpose of the developed nursing care standards and fill out the structured interview sheet (tool I) to assess nurse's knowledge preimplementation of nursing care protocol and the researcher fill out the observation checklist sheet (tool II) to assess nurse's practice preimplementation of nursing care standards.

- The researcher scheduled with them the teaching sessions for both theory and practice and the nurses were divided into small groups, each group contains 3-4 nurses. Teaching has been implemented for nurses in terms of sessions and teaching on the spot during their official working hours. There were a total of 10 sessions. The duration of each session was 30-45 minutes, including 10 minutes for discussion and feedback.

- The effect of the designed nursing care protocol was reached through comparing level of nurse's knowledge and practice pre and post implementing of nursing care protocol has been evaluated by the researcher through filling the study tool (I,II). 


\section{Results}

Table (1): Distribution of Socio-Demographic Characteristics Of The Studied Nurses ( $n=38$ ).

\begin{tabular}{|c|c|c|c|c|c|}
\hline & \multicolumn{2}{|c|}{ Pre $(n=35)$} & \multicolumn{2}{|c|}{ Post $(n=35)$} & \multirow{2}{*}{ P-value } \\
\hline & No. & $\%$ & No. & $\%$ & \\
\hline \multicolumn{5}{|l|}{ Age } & \multirow{5}{*}{0.962} \\
\hline $18-<25$ & 16 & 45.7 & 17 & 48.6 & \\
\hline $25-<35$ & 11 & 31.4 & 10 & 28.6 & \\
\hline$\geq 35$ & 8 & 22.9 & 8 & 22.9 & \\
\hline Mean \pm SD & \multicolumn{2}{|c|}{$32.17 \pm 9.25$} & \multicolumn{2}{|c|}{$30.91 \pm 10.74$} & \\
\hline \multicolumn{5}{|l|}{ Marital status } & \multirow{3}{*}{0.810} \\
\hline Single & 19 & 54.3 & 20 & 57.1 & \\
\hline Married & 16 & 45.7 & 15 & 42.9 & \\
\hline \multicolumn{5}{|l|}{ Qualification } & \multirow{3}{*}{--} \\
\hline Nursing diploma & 21 & 60.0 & 21 & 60.0 & \\
\hline Nursing Technical Institute & 14 & 40.0 & 14 & 40.0 & \\
\hline \multicolumn{5}{|l|}{ Years of experience: } & \multirow{6}{*}{0.995} \\
\hline$<1$ year & 12 & 34.3 & 13 & 37.1 & \\
\hline $1-<3$ years & 3 & 8.6 & 3 & 8.6 & \\
\hline $3-<5$ years & 2 & 5.7 & 2 & 5.7 & \\
\hline$\geq 5$ years & 18 & 51.4 & 17 & 48.6 & \\
\hline Mean \pm SD & \multicolumn{2}{|c|}{$4.33 \pm 2.17$} & \multicolumn{2}{|c|}{$4.82 \pm 1.97$} & \\
\hline \multicolumn{5}{|c|}{ Previously giving nursing care to patients } & \multirow{3}{*}{$0.000^{*}$} \\
\hline Yes & 0 & 0.0 & 35 & 100.0 & \\
\hline No & 35 & 100.0 & 0 & 0.0 & \\
\hline
\end{tabular}

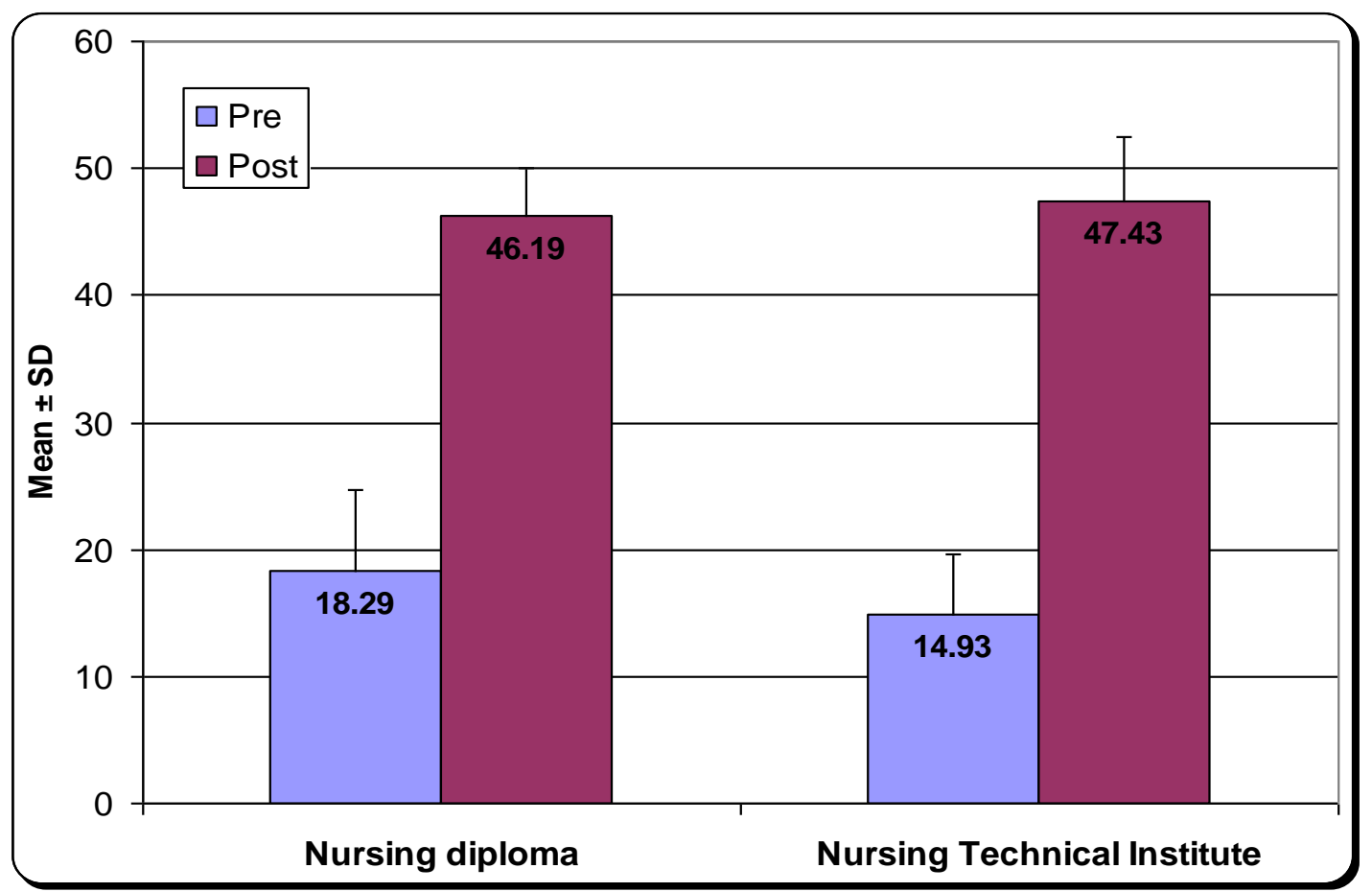

Figure (1): Relationship between nurse's knowledge score and their sociodemographic characteristic (Qualification) post implementing of designed nursing care protocol. 


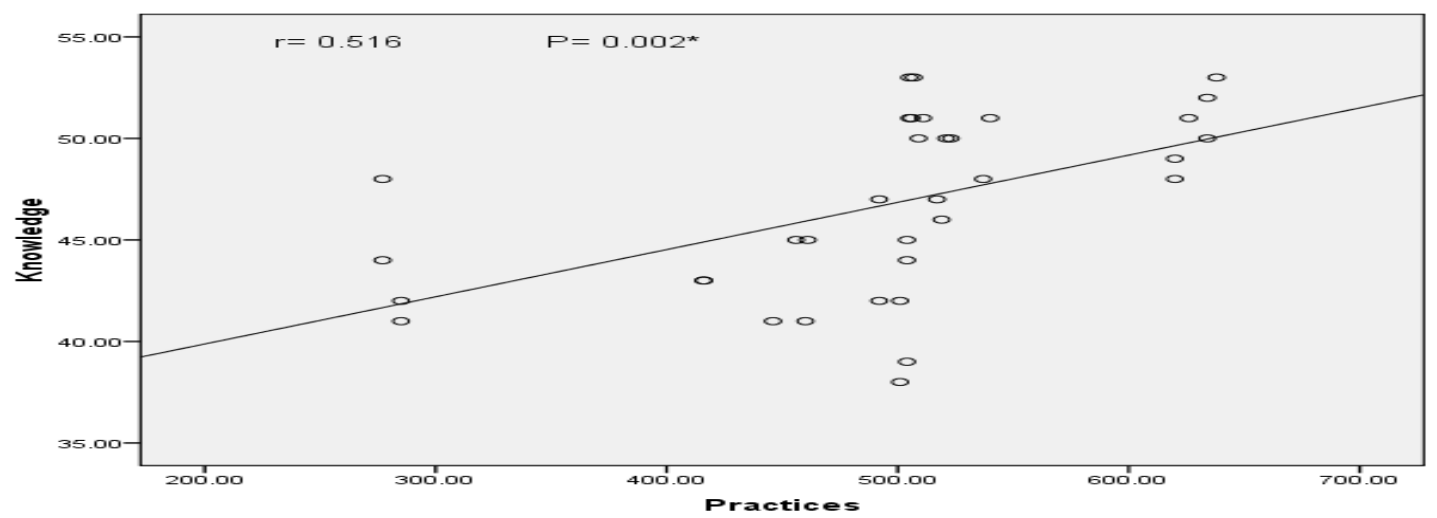

Figure (2): Correlation between knowledge and practices as regard pre and post implementing of designed nursing care protocol for patient undergoing unstable angina $(n=38)$.

Table (2): Total mean knowledge scores obtained by nurses pre and post implementing designed nursing care protocol for patient undergoing unstable angina $(n=35)$.

\begin{tabular}{|c|c|c|c|c|c|c|c|c|}
\hline \multirow{3}{*}{ Item of knowledge } & \multicolumn{4}{|c|}{ Pre $(n=35)$} & \multicolumn{4}{|c|}{ Post $(n=35)$} \\
\hline & \multicolumn{2}{|c|}{ Unsatisfactory } & \multicolumn{2}{|c|}{ Satisfactory } & \multicolumn{2}{|c|}{ Unsatisfactory } & \multicolumn{2}{|c|}{ Satisfactory } \\
\hline & No. & $\%$ & No. & $\%$ & No. & $\%$ & No. & $\%$ \\
\hline $\begin{array}{l}\text { Knowledge of anatomy and } \\
\text { physiology of the heart }\end{array}$ & \multicolumn{4}{|c|}{$6.11 \pm 2.07$} & \multicolumn{4}{|c|}{$12.91 \pm 1.38$} \\
\hline Description of the heart & 19 & 54.3 & 16 & 45.7 & 2 & 5.7 & 33 & 94.3 \\
\hline Heart functions & 9 & 25.7 & 26 & 74.3 & 3 & 8.6 & 32 & 91.4 \\
\hline Heart structure & 11 & 31.4 & 24 & 68.6 & 1 & 2.9 & 34 & 97.1 \\
\hline Function of coronary arteries & 30 & 85.7 & 5 & 14.3 & 2 & 5.7 & 33 & 94.3 \\
\hline $\begin{array}{l}\text { Knowledge about unstable } \\
\text { angina }\end{array}$ & \multicolumn{4}{|c|}{$2.03 \pm 1.07$} & \multicolumn{4}{|c|}{$3.77 \pm 0.55$} \\
\hline Definition & 16 & 45.7 & 19 & 54.3 & 0 & 0.0 & 35 & 100.0 \\
\hline Signs and symptoms & 5 & 14.3 & 30 & 85.7 & 0 & 0.0 & 35 & 100.0 \\
\hline Complications & 18 & 51.4 & 17 & 48.6 & 7 & 20.0 & 28 & 80.0 \\
\hline Risk factors & 22 & 62.9 & 13 & 37.1 & 0 & 0.0 & 35 & 100.0 \\
\hline Chest pain & 6 & 17.1 & 29 & 82.9 & 5 & 14.3 & 30 & 85.7 \\
\hline Precipitating factors & 35 & 100.0 & 0 & 0.0 & 35 & 100.0 & 0 & 0.0 \\
\hline Laboratory investigations & 33 & 94.3 & 2 & 5.7 & 0 & 0.0 & 35 & 100.0 \\
\hline $\begin{array}{l}\text { Knowledge about nursing } \\
\text { cares for patients with } \\
\text { unstable angina }\end{array}$ & \multicolumn{4}{|c|}{$8.80 \pm 4.52$} & \multicolumn{4}{|c|}{$30.00 \pm 3.08$} \\
\hline $\begin{array}{l}\text { Immediate nursing care on } \\
\text { admission }\end{array}$ & 26 & 74.3 & 9 & 25.7 & 0 & 0.0 & 35 & 100.0 \\
\hline Drug administration & 9 & 25.7 & 26 & 74.3 & 0 & 0.0 & 35 & 100.0 \\
\hline Side effects of B-blockers & 29 & 82.9 & 6 & 17.1 & 7 & 20.0 & 28 & 80.0 \\
\hline $\begin{array}{l}\text { Nursing procedures to relieve } \\
\text { chest pain }\end{array}$ & 30 & 85.7 & 5 & 14.3 & 0 & 0.0 & 35 & 100.0 \\
\hline Daily nursing care & 32 & 91.4 & 3 & 8.6 & 0 & 0.0 & 35 & 100.0 \\
\hline $\begin{array}{l}\text { Nursing instructions for } \\
\text { patients before discharges }\end{array}$ & 34 & 97.1 & 1 & 2.9 & 0 & 0.0 & 35 & 100.0 \\
\hline $\begin{array}{l}\text { Nursing instructions for using } \\
\text { nitro-glycerin }\end{array}$ & 34 & 97.1 & 1 & 2.9 & 1 & 2.9 & 34 & 97.1 \\
\hline $\begin{array}{l}\text { Nursing precautions about } \\
\text { giving anti-coagulants }\end{array}$ & 35 & 100.0 & 0 & 0.0 & 10 & 28.6 & 25 & 71.4 \\
\hline Total score of knowledge & \multicolumn{4}{|c|}{$16.94 \pm 5.98$} & \multicolumn{4}{|c|}{$46.69 \pm 4.35$} \\
\hline
\end{tabular}


Table (3): Frequency distribution of the level of nurses` knowledge as regard pre and post implementing of designed nursing care protocol $(n=38)$.

\begin{tabular}{|l|c|c|c|c|c|}
\hline \multirow{2}{*}{ Total score knowledge } & \multicolumn{2}{c|}{ Pre $(\mathbf{n}=\mathbf{3 5})$} & \multicolumn{2}{c|}{ Post $(\mathbf{n}=\mathbf{3 5})$} & \multirow{2}{*}{ P-value } \\
\cline { 2 - 6 } & No. & \% & No. & \% & \\
\hline Unsatisfactory & 34 & 97.1 & 0 & 0.0 & \multirow{2}{*}{$0.000^{*}$} \\
\hline Satisfactory & 1 & 2.9 & 35 & 100.0 & \\
\hline
\end{tabular}

*Statistical significant differences ( $P$-value)

Chi-square test

Table (4): Total mean practice scores obtained by nurses pre and post implementing designed nursing care protocol for patient undergoing unstable angina $(n=35)$.

\begin{tabular}{|l|c|c|c|c|c|}
\hline \multirow{2}{*}{ Nurses practice } & \multicolumn{2}{c|}{ Pre $(\mathbf{n = 3 5})$} & \multicolumn{2}{c|}{ Post $(\mathbf{n = 3 5})$} & \multirow{2}{*}{ P-value } \\
\cline { 2 - 5 } & No. & \% & No. & \% & \multirow{2}{*}{$0.000^{*}$} \\
\hline Total level of practices & 35 & 100.0 & 4 & 11.4 & \\
\hline Inadequate & 0 & 0.0 & 31 & 88.6 & \\
\hline Adequate & \multicolumn{3}{|l|}{}
\end{tabular}

*Statistical significant differences (P-value)

Chi-square test

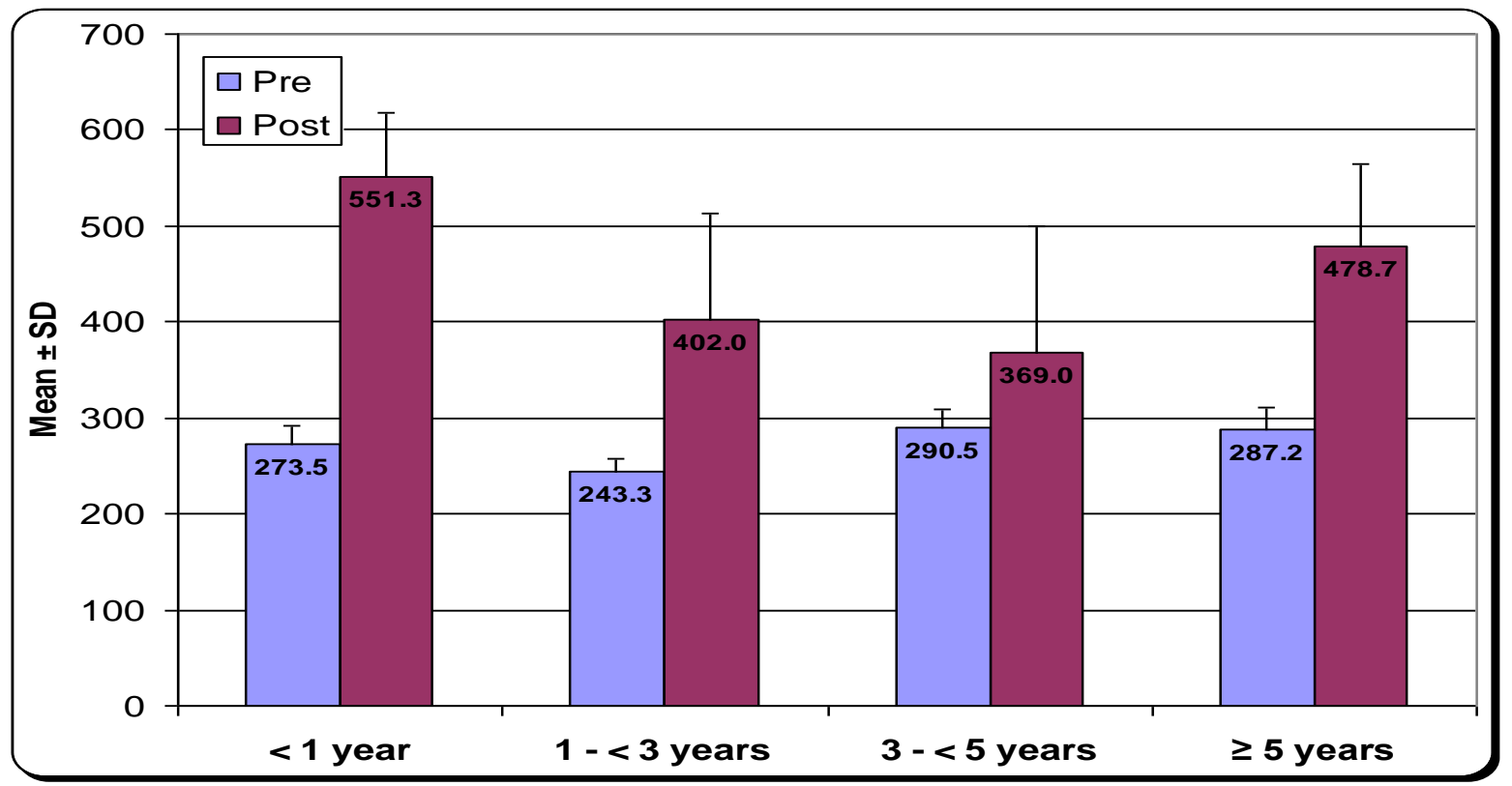

Figure (3): Relationship between total nurse's practice score and socio-demographic (Years of experience) pre-implementing nursing care protocol $(n=35)$.

Table (1): Clarified that; the majority of the nurses $(48.6 \%)$ their age ranged from 18 to $25 y e a r s$ and have diploma degree. $(60.0 \%)$ of them were single, their experiences were more than 5 years $(51.4 \%)$. The majority of the nurses $(100.0 \%)$ had no in-service training courses related to patients with unstable angina.

Figure (1): Shows that; there was a significant difference between nurse's knowledge scores and their qualification, it was found that in diploma and technical institute nurses had improvement level of knowledge in the post of designed nursing care protocol.

Figure (2): Reveals that; there was a significant relation $(\mathrm{p}=0.002)$ between total score of knowledge and a total score of practice post implementing developed of nursing care practice.

Table (2): Demonstrates that; the majority of nurses had a satisfactory level of knowledge in post implementing designed nursing care protocol $(100.0 \%)$ with significant difference $(\mathrm{P}<0.000)$.

Table (3): Demonstrates that; the majority of nurses had a satisfactory level of knowledge in post 
implementing designed nursing care protocol $(100.0 \%)$ with significant difference $(\mathrm{P}<0.000)$.

Table (4): Demonstrates that; the majority of nurses had a satisfactory level of practice in a post designed nursing care protocol for patient with $(\mathrm{P}<0.0001)$.

Figure (3): Shows that; there was a highly statistically significant difference regarding ( $p>0.12$, 0.006)total nurse's practice score and year of experience for a patient undergoing unstable angina.

\section{Discussion}

Coronary care unit nurse should be qualified enough to care for patients because those patients need special nursing care; standard nursing care to improve their conditions and to help in preventing or reducing potential complications. Nurses should develop their own standards of care and the profession should agree on acceptable levels of excellence. Nurses are planned, systematic and focused on mutually agreed goals in which standards of care influence nursing practice, education, and management (Huston, 2003).

The results of the present study showed; that the majority of nurses were aged from $18-25$ years. The all of the nurses were female, more half of them were single, and the nursing diploma was the highest proportion, in half of them, the most of the nurses have experiences more than 5 years and the all of them have no in-service training courses related to unstable angina.

(Ahmed, 2014); in the same line with the current study findings conducted a study in cardiothoracic surgery department, intensive care unit, and operating room at Assiut University Hospital entitled "Developing nursing care standards for patients coronary artery bypass grafting at Assiut University Hospital". reported that, the majority of nurses were female, nursing diploma was the highest proportion, less than half of them have an experience more than five years and all of them have no in-service training courses related to standards of nursing care for patients with coronary artery bypass grafting.

As regard nurse's knowledge, the current study showed that pre-implementing nursing care standards showed the unsatisfactory level of nurse's knowledge of the anatomy of the heart, coronary arteries, and standards care of patients undergoing unstable angina, which reflects the lack of their scientific preparation. Post implementation of nursing care standards showed an improvement in the nurses' level of knowledge regarding the care offered to unstable angina patients. The findings indicate that a good improvement in the mean knowledge scores after implementation of nursing care standards.
So, we can conclude from the data collected and analysis in the present study that all studied nurses weren't properly prepared prior to their working and/or dealing with such unstable angina patients and really they got their experience while being there, working and managing the patients in the real life emergency situations.

In this respect (Change, 2006), mentioned that nurses must be able to expand their knowledge of this area through ongoing education, Journal, and seminars. Consequently, teaching programs for nursing staff constitute an important part. These programs are urgently designed to assess nursing staff in developing and enhancing the skills needed to provide high standards of care to their patients.

The current study revealed a great improvement in the level of nurse's practice post implementing nursing care protocol in all items. This has been concluded by the presence of significant differences between results of pre and post implementing nursing care protocol. This finding indicated that skills can be easily improved, especially if linked with their relevant scientific base of knowledge.

The results of the present study showed significant difference between level of nurses' knowledge and their practice observed during pre implementing nursing care standards. This may be attributed to the majority of the nurses were adults, they got their experience while being there, working and managing the patients in the real life emergency situations. In this respect, (WHO, 2002) ; which found that in order to maintain and improve the quality of patient care, continuous data collection, documentation and analyzing patient information is essential.

\section{Conclusion}

In the light of the current study it can be concluded that, Implementation of designed nursing care protocol for patients with unstable angina shows a significant improvement in nurses' knowledge and practice.

\section{Recommendations}

- Continued nursing education and inservice training programs on coronary care unit should be well organized within Aswan University Hospital and equipped with the necessary educational facilities and materials necessary to upgrade the knowledge and skills of practicing nurses, which will be reflected on better outcome and service for inpatients.

- Nurses should add to their routine obligations the regular reading of up-to-date references (periodicals, textbooks, etc.). They should always 
be encouraged to attend scientific meetings and conferences to keep pace with the rapidly growing wealth of knowledge and practice necessary for proper nursing service.

- Newly employed nurses in coronary care unit are required to successfully complete a test of basic knowledge and skills before assuming independent responsibility for patient care.

- Replication of the study on larger random sample acquired from different geographical areas in Egypt to figure out the main aspect of this problem, so further research studies are highly recommendation to gather in depth knowledge about nursing care for patients undergoing unstable angina.

\section{References}

1. Ahmed, G., (2014): Developing nursing care standards for patient with coronary bypass grafting at Assuit University Hospital .thesis Submitted for Partial Fulfillment of the Requirement of Doctor Degree in Adult (Medical- Surgical) Nursing, faculty of nursing Assiut

2. American College of Cardiology Foundation \& the American Heart Association, (2013): pocket guideline, management of unstable angina and myocardial infarction. Adopted From: http://content.onlinejacc.org/ on 10/20/2013

3. Change, J., (2006): Principles of Microsurgery. Published in the internet by e Medicine: http://www.emedicine.com/plastic/topic262.html

4. Dirksen, Patricia, Graber O'Brien, Linda Bucher.(2009): Medical-Surgical Nursing, $7^{\text {th }}$ ed,chapter63, pp 1659-1661.

5. Huston, B., (2003): Quality health care in an area of diminished resources, Journal of Nursing Care Quality, 18(4), pp. 295- 301.

6. Ian, J., Sarembock, M., ChB, M., FAHA, FACC, et al., (2009): Atlas of Investigation and Management angina, other cases of myocardial ischemia ,oxford center , $7^{\text {th }}$ ed, pp. 11-14.

7. Kristen J., (2009): AJN, May, vol, 109,NO.5.

8. Lee, G., Dennis, A., (2014): Acute myocardial infarction. In: Cecil textbook of medicine, 22nd edition, EB. Saunders Company, pp. 304-24.

9. National Library Of Medicine, (2013): http://www.NLM.microsurgery.com.

10. Shell, S. (1999): Microvascular tissue transfer. Perioperative nursing consideration. Aorn J; 49(4): 1032-6,1038-40,1024-3. published in the pubmed by national Library of Medicine; http://www.NLM.microsurgery.com
11. WHO (2002): Fifty -fifth world health assembly Quality of care: patient safety Report by the Secretariat Medication A55/ 13 Provisional agenda item 13.923.

12. World Health Report, (2012): WHO. Available at: http://

www.who.int/whosis/whostat/EN_WHS08_TOC intro.pdf.

13. Janice R., Celia L., Elizabeth N., Helen K., Martin A., (2009): Managing and coordinating Nursing care, $5^{\text {th }}$ ed , chapter 7, pp. 359-264. 